\title{
Four Actionable Bottlenecks and Potential Solutions to Translating Psychiatric Genetics Research: An Expert Review
}

\author{
Jessica L. Bourdon ${ }^{a}$ Rachel A. Davies ${ }^{b} \quad$ Elizabeth C. Long ${ }^{c}$ \\ aDepartment of Psychiatry, Brown School of Social Work, Washington University in St. Louis, St. Louis, MO, USA; \\ byerkes National Primate Research Center, Division of Behavioral Neuroscience and Psychiatric Disorders, Emory \\ University, Atlanta, GA, USA; ' $E d n a$ Bennett Pierce Prevention Research Center, Pennsylvania State University, \\ University Park, PA, USA
}

\section{Keywords}

Translational science $\cdot$ Psychiatric disorders · Genetics

\begin{abstract}
Background: Psychiatric genetics has had limited success in translational efforts. A thorough understanding of the present state of translation in this field will be useful in the facilitation and assessment of future translational progress. Purpose: A narrative literature review was conducted. Combinations of 3 groups of terms were searched in EBSCOhost, Google Scholar, and PubMed. The review occurred in multiple steps, including abstract collection, inclusion/exclusion criteria review, coding, and analysis of included papers. $\boldsymbol{R} \boldsymbol{e}-$ sults: One hundred and fourteen articles were analyzed for the narrative review. Across those, 4 bottlenecks were noted that, if addressed, may provide insights and help improve and increase translation in the field of psychiatric genetics. These 4 bottlenecks are emphasizing linear translational frameworks, relying on molecular genomic findings, prioritizing certain psychiatric disorders, and publishing more reviews than experiments. Conclusions: These entwined bottlenecks are examined with one another. Awareness of these bottlenecks can inform stakeholders who work to translate and/or utilize psychiatric genetic information. Potential so-
\end{abstract}

lutions include utilizing nonlinear translational frameworks as well as a wider array of psychiatric genetic information (e.g., family history and gene-environment interplay) in this area of research, expanding which psychiatric disorders are considered for translation, and when possible, conducting original research. Researchers are urged to consider how their research is translational in the context of the frameworks, genetic information, and psychiatric disorders discussed in this review. At a broader level, these efforts should be supported with translational efforts in funding and policy shifts.

(c) 2020 S. Karger AG, Basel

\section{Introduction}

Psychiatric disorders are a major burden in the USA, resulting in over USD 300 billion annually in cost from health care expenses, loss of wages, and disability benefits [1]. Among adults, over a quarter of the population will meet criteria for 1 or more psychiatric disorders in a given year [2]. Costs will only continue to increase without effective prevention, detection, treatment, and support for these conditions [3]. The translation of genetic information to the clinic has improved prevention

karger@karger.com

(c) 2020 S. Karger AG, Basel

www.karger.com/phg

Karger!
Jessica L. Bourdon

Department of Psychiatry, Brown School of Social Work

Washington University in St. Louis

4560 Clayton Avenue, St. Louis, MO 63110 (USA)

jlbourdon@wustl.edu 
and treatment of several chronic physical disorders (i.e., nonpsychiatric) [4]. It is possible that the mental health field could similarly benefit from the translation of psychiatric genetics research via the reduction of subsequent morbidity and mortality. Psychiatric genetic information, such as individual-level information (e.g., family history and polygenic risk scores) and population-level information (e.g., gene-environment interplay and the etiology of disorders), can be powerful in genetic counseling by improving self-efficacy and reducing stigma [5-9]. However, a research-to-practice gap exists, whereby psychiatric genetic information about psychiatric disorders is not being integrated into clinical care [10-16].

Historically, the application of genetic information - whether it be nonmolecular epidemiological information (e.g., family heritability estimates from twin studies, gene-environment interplay data) or molecular information (e.g., genome-wide association data, polygenic risk scores, epigenetics) - is lacking in the development of psychiatric disorder prevention and treatment as compared to nonpsychiatric medical conditions such as breast cancer [17-21], cardiovascular disease [4, 22-25], type 2 diabetes [26], and macular degeneration [27]. For example, the incorporation of molecular genomic testing for $B R C A$ variants in clinical settings has led to applications for the diagnosis of breast cancer and more effective treatment [21] as well as effective prevention efforts above and beyond nonmolecular family history information [28]. Scientific understanding of breast cancer patient, researcher, and clinician attitudes toward complex topics, such as the return of incidental molecular genetic findings and the biobanking of DNA samples, has additionally progressed the field $[29,30]$. A comparable level of applicable research knowledge (e.g., molecular genomic findings and insights into stakeholders' attitudes) is not yet available for psychiatric disorders, leaving many to conclude that the application of genetic information to mental health is years away $[4,31,32]$. This supposition is ascribable to the higher polygenicity and complex genetic structure of psychiatric disorders.

Contrasting with the prevailing skepticism toward its near future prospects for translation, the basic science of psychiatric genetics continues to evolve in an innovative, multidisciplinary way. The insistence that this knowledge be similar to that used in translating nonpsychiatric disorders before being useful for translation, however, may undermine the value of psychiatric genetic information that is known. We argue that instead of waiting for more knowledge, the field of psychiatric genetics should consider working toward translation of the knowledge it is rapidly generating. With an intentional re-examination, rebuilding, and informed application of appropriate translational frameworks, psychiatric genetic translational breakthroughs might no longer be relegated to decades away. The first step in this process is to review the state of translating psychiatric genetic research via a narrative literature review.

\section{Strategy}

\section{Search Methods}

A thorough, non-systematic, narrative literature review was conducted in multiple steps (see online suppl. Text 1 for a more thorough explanation of each step; see www.karger.com/doi/10.1159/000510832 for all online suppl. material). Given that the scope of this paper was to summarize a broad area (the translation of psychiatric genetic information) and a specific question was not posited, a narrative literature review was conducted instead of a systematic review [33]. First, all combinations of terms about translation, psychiatric disorders, and genetics were searched. The abstracts from all potentially relevant articles were downloaded and reviewed for inclusion/exclusion criteria (see online suppl. Table 1 and suppl. Text 2).

\section{Search Results}

The first step of the review process ended with $372 \mathrm{ab}-$ stracts that were loosely related to the aims of this paper. After reviewers completed the inclusion/exclusion checklist and coding form and the lead author confirmed the articles, 157 abstracts met criteria for inclusion. Eleven of these were duplicates and 32 were not peer-reviewed articles (e.g., conference proceedings, commentaries, and poster presentations) or did not meet inclusion criteria after a full read, resulting in 114 articles for analysis. Online suppl. Table 2 contains a list of the final articles included in the review. Limitations of the search and the review can be found in online suppl. Text 4 .

\section{Review Findings}

The current narrative literature review examined the state of the science of translating psychiatric genetic information into clinical care. Evidence was found for 4 areas of this research that, if thoroughly examined, may 
help to propel translation in this area further. Specifically, there are 4 bottlenecks that contribute to the hindrance of nuanced, innovative, and progressive thinking in this area. These will be discussed in turn and are as follows: emphasizing linear translational frameworks, relying on (and waiting for) molecular genomic findings, prioritizing certain psychiatric disorders, and publishing more reviews than experiments.

\section{Part 1: Emphasizing Linear Translational Frameworks}

Differences between the relationship of genetics to disease in psychiatric and nonpsychiatric contexts raise questions about using the same type of translational frameworks for both types of disorders. Admittedly, nonMendelian, chronic physical conditions and psychiatric disorders are all "complex" traits with an interplay of genetic and environmental etiological factors. Yet, the genetic structure of psychiatric disorders consists of a greater number of alleles with smaller penetrance, meaning that each gene contributes little to the overall variation of the trait $[34,35]$. There is also evidence for nonadditive genetic factors that contribute to psychiatric disorders, reducing the chances of successful molecular genetic studies [34]. These key differences between nonpsychiatric and psychiatric disorders could limit the generalizability of the translational frameworks used for nonpsychiatric disorders to psychiatric ones.

Specifically, 2 frameworks that are highly prevalent across all health-related research fields follow a linear structure [36] and have historically spearheaded advancements in medicine and other fields with a biological focus $[37,38]$. These linear frameworks are bench-to-bedside (i.e., research that begins at the biological level and can eventually lead to clinical trials or randomized controlled trials) $[39,40]$ and precision medicine (i.e., the use of biological information to improve patient health that may be acquired from the bench or beyond and is specific to particular treatment contexts and individual patient needs) $[41,42]$. Success in these frameworks is predicated on the ability to uncover the underlying biological basis of disease (e.g., genetics and neurobiology) and convert it to innovation at the level of patient care. Accordingly, such frameworks have been successful in nonpsychiatric fields but have had little effect when applied to the genetics of psychiatric disorders $[4,31,32]$. Each framework will be discussed in turn below.

Translating Psychiatric Genetics Research

\section{Bench-to-Bedside Research}

It is common for bench-to-bedside research to utilize animal models and biomarker development, which are consistent approaches to psychiatric genetic translation. Animal models are regularly used to investigate complex traits (e.g., depression) without questioning or justifying the translational framework. The assumption that genetic research at the animal level will eventually translate to psychiatric precision medicine because a bench-to-bedside framework has been successful in translating and utilizing the genetic information for other complex but nonpsychiatric disorders is often implicit in such discussions [43-55]. It has seemingly become common for studies to explicitly use the term "precision" or "personalized" medicine when reviewing literature that is strictly at the bench-to-bedside level (e.g., animal models and drug development preclinical trials) and/or make it clear that precision medicine is the end goal of current bench-tobedside efforts [55-61]. Occasionally, there is a call for the need to translate genetic findings from animal models into patient-specific treatment while simultaneously acknowledging that the biological roots of psychiatric disorders are still being uncovered $[45,62]$, a paradox that arguably feeds the assumption that linear translational frameworks should be used to translate psychiatric genetic information. Biomarker development suffers from the same assumption as animal models. It is common to discuss past successes with nonpsychiatric chronic or Mendelian disorders and how future psychiatric treatment will likewise be enhanced by biomarker development for psychiatric disorders [63-66]. That is not to say that such claims are not true, but that they do not rely on strong evidence.

Thus, the field might benefit from critical reflection on the time and place to rely on bench-to-bedside translation. For example, Hariri and Holmes [67] argue that translational efforts should also emphasize investigations of non-pharmaceutical treatment processes, supporting their argument with the compelling results of neural circuit manipulation for stress-related disorders in rodent models. Others have argued that new methods (i.e., an integrative research domain criteria approach [RDoC], an established matrix of inter-related domains, and constructs proposed by $\mathrm{NIH}$ ) need to be taken to be able to effectively use information from the "bench" $[68,69]$, especially as epigenetics becomes more common [70].

\section{Precision Medicine Research}

Similar to research using a bench-to-bedside framework, research that uses a precision medicine frame- 
work makes explicit [16, 71-83] and implicit [84-101] comparisons between the translation of genetic information to psychiatric and nonpsychiatric care. These comparisons give way to the assumption that linear frameworks will undoubtedly work, albeit in the future. Notably, several researchers have taken care to acknowledge that it will take more time to translate psychiatric genetic information to patient care due to the non-Mendelian nature and heterogeneity of such disorders [102-112]. There has also been a recent increase in the discussion of pharmacogenetic treatment for psychiatric disorders, specifically, examining metabolism rates of currently approved psychiatric medications, response to treatment, gene-drug interactions, or other genetic biomarker differences among individuals [94, $113,114]$, or reviewing the literature on such treatments $[82,110,115-118]$.

\section{Moving Linear Translation Forward}

There are ways to expand linear frameworks to allow for more reflection. First, bench-to-bedside research often leads into precision medicine; discussing both lenses within a research study could offer a more thorough discussion about the translation of psychiatric genetic research. For example, Damianco and colleagues [119] discussed genetics in terms of biomarkers and preclinical models from a bench-to-bedside approach and then the precision medicine application of those biomarkers for early identification and treatment for psychiatric disorders from an $\mathrm{RDoC}$ perspective. Foley and colleagues [120] followed a similar structure, discussing the need for gene and drug discovery (bench-to-bedside framework) that will help us to understand molecular mechanisms and eventually improve treatment (precision medicine), possibly with the use of clustered regularly interspaced short palindromic repeats (CRISPR). Other papers that also discussed bench-to-bedside research within the lens of future precision medicine include Siegel and colleagues [121], Stern and colleagues [122], Tomasi and colleagues [117], and Zayats and Neale [123]. While a justification for these translational frameworks is not provided, such research highlights the potential benefits of combining linear translational frameworks more fully than research that solely works from one framework or the other.

Second, several researchers acknowledge the inherent genetic differences between psychiatric and nonpsychiatric disorders and that precision medicine based on psychiatric genetic information is unlikely $[105,124,125]$ or at least will take longer than anticipated [126]. Precision medicine will likely have to integrate several biological mechanisms into several possible treatments [124] or take another yet-to-be-determined approach in order to be successful for psychiatric genetics [125]. Psychiatric disorders are too complicated genetically as well as phenotypically for the successful application of the same version of precision medicine that has worked for chronic physical disorders [125]. In the meantime, it has been recommended that patients' other biological, social, and clinical information be considered when prescribing psychiatric medication.

Third, many researchers have posited their own translational models that overcome flaws in linear frameworks. Amare and colleagues [127] discussed predictive, preventive, and personalized medicine, an extension of traditional precision medicine. Their predictive, preventive, and personalized medicine framework offers 3 alternative/complementary strategies to pharmacogenomics (the primary way to translate psychiatric genetic information in precision medicine): (1) diagnostic, therapeutic, or prognostic genetic testing based on candidate genes; (2) combine "-omics" data; and (3) combine genomics information with other predictors (-omics, neurological information, and clinical characteristics). Bickman and colleagues' [128] framework, precision mental health, is also an extension of precision medicine and specifically calls NIH to move beyond genetic factors as the sole focus of precision medicine in psychiatry and embrace an RDoC perspective. Wittchen and colleagues [129] also offered a framework, an integrative translational model that explicitly does assume that what worked in the past will work in the future. Their framework specifically contrasts itself with precision medicine. However, genetics made up a small component of this discussion. While working from a precision medicine perspective, Hutchison [124] noted the flaws of precision medicine (sample size, lack of clinical translation, lack of replication, and emphasis on univariate approaches) and offers a model that uniquely combines 2 networks, neural and genetic, that should be targeted when treating substance use disorders. Herbert and colleagues [130] presented the IMPACT model for psychiatric treatment that includes pharmacogenetic testing across a range of psychiatric disorders. Relatedly, several studies $[59,114,126,131]$ offer roadmaps for how to navigate translation in their review.

Fourth, 3 studies pointed out ways that genetic studies are biased and exclusive toward individuals who are not of European descent [59, 108, 109]. Peterson and colleagues [59] noted flaws in current molecular genomic methods and offered suggestions for improving genetic 
ancestral analyses. While such a method-focused study is at the bench-to-bedside level, implications will undoubtedly have an impact on precision medicine in the future. Similarly, Martin and colleagues [108, 109] highlighted ways that molecular genomic methods only benefit European descendants and that ancestral diversity needs to be prioritized in future studies.

\section{Moving beyond Linear Frameworks}

An option to effectively translate psychiatric genetic information is to utilize nonlinear frameworks such as dissemination and implementation (D\&I). D\&I requires simultaneous integration of information from many stakeholders and focuses on the ecology of the service delivery system [36, 132-134]. Such a framework offers novel, systematic, and comprehensive ways to address the translational gap within psychiatric genetics [135]. It can integrate psychiatric genetic information into care quickly and effectively because it is designed to close researchto-practice gaps as each side of the gap informs the other $[136,137]$.

Unfortunately, to our knowledge, there are no translational psychiatric genetic articles that solely utilize a D\&I framework. However, there are many articles that incorporate aspects of D\&I (e.g., include stakeholders, ecological theory, and focus on implementation) $[5,109$, 121, 131, 138-145]. For example, Finn and Smoller [139] were early proponents of using psychiatric genetic counseling in clinical care (after more evidence and empirical support). Costain and colleagues [5] took this a step further by showing that psychiatric genetic counseling (which relies on genetic epidemiological information) improves disorder knowledge and decreases stigma for patients with schizophrenia. Such a study clearly overlaps with D\&I by disseminating information to patients (a key stakeholder group) via an implementation strategy and evaluating the effectiveness of that strategy. Drury and Cuthbert [138] continued the discussion of $\mathrm{RDoC}$, beginning from a precision medicine perspective and expanding in a nonlinear, D\&I-esque direction by specifically calling for an inclusion of clinicians and other transdisciplinary collaborators to progress translation. Harold and colleagues [140] offered clear suggestions for clinicians on how to incorporate psychiatric genetic information (genetic epidemiological and molecular) information into care with the help of families. This clear pathway from research to practice is at the heart of D\&I via the inclusion of multiple stakeholders (parents, children patients, and clinicians). Similarly, Roos [142] discussed the role of genomics, recurrent risk, and family history in clinical care for schizophrenia, as did Vortsman and colleagues [143] when discussing the implementation of pharmacotherapy into the clinical care of autism spectrum disorder. Finally, Hendershot [141] offered a rare discussion of when and how to implement genomic information (i.e., pharmacogenomics) into evidence-based practice guidelines for alcohol use disorder and that there is a need for efficient, not just effective, translation.

\section{Summary: Part 1}

Overall, the vast majority of research on the translation of psychiatric genetic information occurs from linear bench-to-bedside and precision medicine frameworks and make implicit and explicit assumptions that these frameworks will lead to clinical and pharmacological improvements in patient care. These assumptions leave little room for discussion of treatment impact or an objective evaluation of whether linear frameworks are the right path forward when translating psychiatric genetic information. One contributing factor is that funding agencies and programs have long supported a linear translational framework, making it difficult for researchers to move beyond it. Thus, funding and policy shifts need to occur supporting a diversity of translational frameworks if nonlinear approaches are to be efficiently adopted.

Fortunately, studies in the last few years have seen a slight increase in studies that discuss the genetic differences between psychiatric and nonpsychiatric disorders, calling into question how precision medicine will function in psychiatry. As will be discussed in Part 2 below, these assumptions likely limit the type of genetic information that is attempted to be translated. Molecular genomic information, which is still being actively researched for psychiatric disorders, is inherently the information of choice within bench-to-bedside and precision medicine frameworks. Two key options have presented themselves that may move the field of psychiatric genetics forward. First, we can continue the push to move linear frameworks forward. Several articles were outlined that question the use of precision medicine, offer new frameworks, and reflect upon the fact that relatively little genetic information is known about psychiatric disorders. Second, we can simultaneously embrace nonlinear, ecological-based frameworks such as D\&I that value partnerships with stakeholders. These frameworks might immediately impact patient care by identifying innovative ideas about what translation can look like for psychiatric genetics and what type of information is translated. 


\section{Part 2: Relying on Molecular Genomic Information}

The second bottleneck that has dominated the translation of psychiatric genetic information is the disproportionate reliance on molecular genomic information over nonmolecular epidemiological forms of genetic information (e.g., heritability estimates, family history, and geneenvironment interplay data). This is intrinsically linked to the first bottleneck of emphasizing linear frameworks, because linear frameworks rely on biological (e.g., molecular genomic) information. The exclusion of nonmolecular genetic information is worrisome because such information may be more accessible to patients and other stakeholders and has been shown to be efficacious in treatment settings [9]. Recent public health efforts have started to shift the narrative around the translation of genetic information broadly $[13,17,146]$ and psychiatric genetics specifically $[12,147]$ to include this type of genetic information. This shift involves turning some attention away from molecular genomic and epigenetic information and opening up the possibility of utilizing family history, heritability, and other genetic epidemiological sources of information either singularly or in tandem with molecular genetic information $[12,13]$. Nonmolecular information is still relevant, even in a "genomics" era, as it may present genetic information in a more readily accessible form. This improves the likelihood of stakeholder understanding $[12,148]$, thereby reducing a significant barrier to the translation of genetic information for psychiatric disorders. For example, nonmolecular genetic information like family history could be used to identify at-risk persons (similar to Meiser et al. [149]) who are then targeted for behavioral interventions. Such a translational pipeline would be a natural extension of work done by psychiatric genetic counselors who provide patients and family members with genetic information about schizophrenia $[5,6]$.

\section{Molecular Genomic Information}

Research that discuss the translation of molecular psychiatric genetic information is typically done via a review $[16,43,44,46-48,50-52,62-64,66,69,71,73,74,76-82$, $84-89,93,96,97,99,101,102,104-107,120,127,138]$; few experimental articles exist (see Part 4 below). Reviews often include potential ways that molecular genomic information could help the field. Topics of interest range from summarizing different aspects of precision medicine, such as the pharmacogenetics of alcohol use disorder [101] and genetic testing for autism spectrum disorder (ASD) [89], to outlining clinical barriers to precision medicine in psychiatry such as lack of evidence and training $[81,143]$ (see Part 3 for a discussion of specific psychiatric disorders studied).

Such research often discusses molecular genomics in a broad context with few or no specific examples of copy number variants, genome-wide association findings, or polygenic risk scores $[45,54,55,59,72,90,100,103,108-$ $111,116,119,123-125,128,129,150-153]$, but there is a recent trend of reviewing specific biomarkers and potentially actionable molecular variants (e.g., for gene-drug interactions) in-depth $[53,56-58,61,82,83,112,114$, $115,117,118,121,122,131,144,154]$. For example, Bousman, et al. [115] provided a review of the gene-drug interactions of 91 psychotropic drugs and 16 genetic variants across 5 genes, giving rationale for listing those 16 variants as the minimum panel for pharmacogenetics testing. There is also a growing trend of including or focusing on epigenetics (the study of gene expression) [53, $56,61,65,70,80,101,116,118,153]$. Luoni and Riva [65], for example, provided a nice overview of the mechanisms that regulate miRNA biogenesis and the possibility of using that as a biological target in pharmacological interventions for psychiatric disorders.

\section{Nonmolecular Genetic Information}

The research on translating the genetic epidemiology of psychiatric disorders $[5,6,126,139,140,142,155]$ is scarce. Occasionally, the translation of both genetic epidemiology and molecular genomics are discussed together $[75,153,156,157]$. Rende and Slomkowski [155] stand out for providing a rare behavioral genetic perspective by discussing the rationale for using a family design for studying the translation of genetic risk for disorders. Such a design can offer a fuller picture of a disorder and subsequent translation to clinical care by incorporating both genetic and environmental information. Bulik et al. [158] further discussed the importance of psychiatric genetic counseling for eating disorders, a field that focuses on family history and other genetic epidemiological information because molecular information is not yet actionable. However, if non-genomic information is mentioned in the context of translating psychiatric genetic information, it is typically done so in passing, such as mentioning heritability or family history in the introduction but not how that information can also be used in clinical care (e.g., Foley et al. [120] and Gandal et al. [76]). On the one hand, this is a missed opportunity because genetic epidemiological information can be more quickly and easily translated. On the other hand, rigorous research is needed to show that inclusion of information such as family 
history in prevention or intervention efforts is useful. Such research is underway in psychiatric genetic counseling centers $[9,158]$. However, the field would benefit from more widespread examination of translating nonmolecular genetic information.

\section{Summary: Part 2}

There is a need to investigate how and when to translate all psychiatric genetic information. To date, there is a demonstrable bottleneck in the literature, where researchers rely on molecular genomic information when reflecting on psychiatric genetics translation. While important, this ignores other genetic information that could improve patient care and prevention efforts. Given that the future of uncovering the molecular genomic basis of psychiatric disorders is unclear, it is urgent to include genetic epidemiological information in translational efforts.

\section{Part 3: Prioritizing Certain Psychiatric Disorders}

So far, each bottleneck has been subsumed by and entwined with the previous one. That trend continues with these last 2 bottlenecks. The third one noted among translational psychiatric genetic research is that certain psychiatric disorders are prioritized over others. This likely stems from the emphasis on linear translational frameworks and reliance on molecular genomic information, because the psychiatric disorders that are most often studied are those for which researchers have uncovered the most genetic markers. Overall, a wide range of psychiatric disorders are represented in the literature - some are individually discussed and others are discussed in combination with other disorders. Comorbidity is sometimes mentioned $[69,76,90,130,156]$, and there are also broad discussions of psychopathology $[44,58,59,67,77,108-$ $112,130,144,153,159]$. Yet, there is a higher representation of disorders for which the most known genetic variants have been discovered to date. These include schizophrenia, ASD, and mood disorders $[45,51,53-56,60,64$, $69,71,73,75-80,89,94-97,100,102,103,107,113,114$, $116,118,119,122,126,127,143,156,157,160]$. This comes as no surprise, but it must be noted that even for disorders such as schizophrenia and bipolar disorder, the genetic variants known are not clinically actionable due to how little genetic variance they account for [34]. This tendency to primarily discuss disorders such as schizophrenia and mood disorders (i.e., the disorders for which the most genetic information is available) may serve to

Translating Psychiatric Genetics Research perpetuate the assumption about the generalizability of linear views of translation as well as the disproportionate emphasis toward molecular genetic information, as discussed above (Parts 1 and 2). Often such articles are reviews, which align with the bottleneck discussed in Part 4 below. For example, Ozomaro and colleagues [80] provided a review of the genetics, epigenetics, and endophenotypes of major depressive disorder, bipolar disorder, and schizophrenia, stating that the groundwork is being laid for precision medicine in psychiatry and that such precision medicine will have an emphasis on biomarkers and imaging.

Other disorders for which the translational applicability of their genetic information has been studied include alcohol use/substance use disorder and other addictions $[46,48,49,57,61,77,82,84-86,91,99,101,121,124,131$, $141,145,151,152]$, anxiety $[52,113,117,118,156,161]$, suicide [98], post-traumatic stress disorder [66, 156], stress [50,67], attention deficit hyperactivity disorder $[55,118,123]$, and eating disorders [158]. Even though these disorders have fewer known genetic markers than schizophrenia, ASD, or mood disorders, most of this research discusses how the few known markers can make a difference. Malter and colleagues [50] discussed the role of the BDNF gene in anxiety and stress and how it can aid in bench-to-bedside translation by bridging human behavioral and imaging genetics with animal models. Similarly, Chen and colleagues [82] reviewed how identifying biomarkers that affect treatment response to smoking cessation can aid in precision medicine of nicotine addiction.

\section{Summary: Part 3}

Psychiatric disorders for which the most genomic information is known, specifically schizophrenia, ASD, and mood disorders, dominate the discussion of translating psychiatric genetic information. This is disproportionate to which disorders are most common in the population. Other internalizing disorders such as anxiety and stress are highly prevalent, and thus, psychiatric genetic translational efforts should actively strive to include a wider range of disorders so that more patients can benefit from this research.

\section{Part 4: Publishing More Reviews than Experiments}

The final bottleneck that is enmeshed with the other 3 is that published articles focus more on reviews than on experiments. This might be expected given the long delay 
between research and practice in linear frameworks such as bench-to-bedside; reviews are easier and faster to generate. To our knowledge, only 14 experimental articles address the translation of psychiatric genetic information $[5,6,49,60,91,92,94,98,113,114,130,145,151,162]$. There is heterogeneity among these articles. For example, Costain and colleagues [5] provided genetic counseling to individuals who had previously been diagnosed with schizophrenia as well as their family members [6]. They noted that perception of recurrent risk improved along with knowledge and etiological attribution about schizophrenia while stigma reduced. Lee and colleagues [94] developed a person-centered algorithm to identify individual patients with schizophrenia who will respond to antipsychotic medications based on molecular markers. Niculescu and colleagues [98] found biomarkers associated with suicide as well as subtypes of suicide (high anxiety, low mood, both, non-affective) that will hopefully improve precision medicine for suicide. Finally, Bradley and colleagues [113] addressed drug metabolism of psychiatric drugs from a pharmacogenomic perspective, offering actionable precision medicine insights.

\section{Summary: Part 4}

Many published articles discuss the potential of translating psychiatric genetic information. Few articles conduct novel experimental research that seeks to move the field of translating psychiatric genetics forward. Specifically, $\sim 12 \%$ of articles included in this review were experimental. This is more than Holmes and colleagues' [163] critique of personalized medicine where they found that the ratio of reviews/commentaries to experimental articles is $25: 1(4 \%)$, but $\sim 12 \%$ is still a low percentage. While it is important to thoroughly discuss translation, it is also necessary to test theories, models, frameworks, and approaches. Only through experimental research we will truly understand the optimal translational framework for each type of psychiatric genetic information and each psychiatric disorder.

\section{Conclusions}

The current narrative review examined the state of translating psychiatric genetic information into clinical care. This was done by dissecting 4 bottlenecks among translational psychiatric genetic research. These bottlenecks were emphasizing linear translational frameworks, relying on molecular genomic findings, prioritizing certain psychiatric disorders, and publishing more reviews than experiments. They are closely entwined, with each subsequent bottleneck subsumed by the previous one. The purpose of this review was not to condemn these bottlenecks but to highlight them and encourage that a balance be struck in the field. Linear translational frameworks (benchto-bedside and precision medicine) are not inherently inappropriate for translating psychiatric genetic information, but given that they have had little success to date, it is worth exploring nonlinear, ecological frameworks such as D\&I. The same is true for relying on molecular genomic findings. For example, it is possible that polygenic risk scores will have clinical implications but likely not for many years [164]. Translating nonmolecular, epidemiological genetic information such as family history, heritability, and etiological attribution would be relatively simpler than translating genomic information due to the fact that this information is already known for all psychiatric disorders. If both of these bottlenecks are overcome, then this will likely lead to more breadth and depth in the types of psychiatric disorders that are studied. Conversely, it is possible that an initial focus on translating psychiatric genetic information on a wider range of disorders (e.g., anxiety, eating disorders, suicide, and alcohol use) will help to break the first 2 bottlenecks. It also cannot be emphasized enough that original experimental research needs to be done in this area. Both quantitative and qualitative research is needed, ideally after partnerships with community members and local clinics are established. This will ensure that the clinical utility of psychiatric genetics is thoroughly assessed. Finally, it bears repeating that funding and policy shifts need to occur to allow these bottlenecks to be fully fixed at the research level.

Hopefully, this review can help stakeholders to reflect upon the framework(s) that they utilize when translating psychiatric genetic information and, when appropriate, seek out less-studied frameworks, less-utilized genetic information, and less-examined psychiatric disorders in an experimental project. Thus, this review has direct implications for all stakeholders involved in psychiatric disorder research and/or clinical care, most immediately for researchers and clinicians. Such future research will help the field to outline which frameworks are best for which psychiatric disorders and for which types of genetic information. This will require increasing knowledge and competence of these 4 interrelated topics (translational frameworks, genetic information, psychiatric disorders, and study design) among stakeholders as well as continued open discussion about this topic. The time is right for such a shift; it is our obligation to determine the best ways to translate psychiatric genetic information. 


\section{Acknowledgements}

We would like to acknowledge Dr. Cassie Overstreet and Ms. Gladys Langi for their help gathering and reading articles in the early stages of this project.

\section{Statement of Ethics}

This study is in compliance with ethical standards; no human or animal subjects were part of this study. The authors followed all ethical guidelines, such as but not limited to disclosing all funding and conflicts of interest, avoiding plagiarism, and following guidelines for authorship.

\section{Conflict of Interest Statement}

None of the authors have any conflicts of interest to disclose.

\section{Funding Sources}

Funding sources related to this project are as follows: J.L.B. was previously supported by T32MH020030 (PI: M. Neale) during the early stages of this project and was supported by NIDA T32 DA 015035 (m/PI: R. Cunningham-Williams and K. Bucholz) during the revise and resubmit stages.

\section{Public Significance Statement}

Translation of psychiatric genetic information has been limited, but thorough reflection and balance of 4 key bottlenecks may bring progress. Stakeholders should note the translational framework that they utilize, the type of genetic information and psychiatric disorder that they study, and whether they publish experimental studies or reviews.

\section{Author Contributions}

J.L.B. gathered articles for the review. J.L.B., R.A.D., and E.C.L. reviewed the articles. J.L.B. wrote the first draft. R.A.D. and E.C.L. provided editorial feedback and guidance. All authors have seen and approved the final version of the manuscript being submitted.

\section{References}

1 Centers for Disease Control and Prevention. Mental health surveillance among adults in the United States. MMWR. 2011;60(Suppl 3): $1-32$.

2 Kessler RC, Chiu WT, Demler O, Walters EE. Prevalence, severity, and comorbidity of twelve-month DSM-IV disorders in the National Comorbidity Survey Replication (NCSR). Arch Gen Psychiatry. 2005;62(6):617-27.

3 Murray CJ, Lopez AD. Global mortality, disability, and the contribution of risk factors: global burden of disease study. Lancet. 1997; 349(9063):1436-42.

4 Vornanen $M$, Konttinen $H$, Kääriäinen $H$, Männistö S, Salomaa V, Perola M, et al. Family history and perceived risk of diabetes, cardiovascular disease, cancer, and depression. Prev Med. 2016;90:177-83.

5 Costain G, Esplen MJ, Toner B, Scherer SW, Meschino WS, Hodgkinson KA, et al. Evaluating genetic counseling for individuals with schizophrenia in the molecular age. Schizophr Bull. 2012;40(1):78-87.

6 Costain G, Esplen MJ, Toner B, Scherer SW, Meschino WS, Hodgkinson KA, et al. Evaluating genetic counseling for individuals with schizophrenia in the molecular age. Schizophr Bull. 2012;40(1):78-7.

7 Hippman C, Ringrose A, Inglis A, Cheek J, Albert AY, Remick R, et al. A pilot randomized clinical trial evaluating the impact of genetic counseling for serious mental illnesses. Clin Psychiatry. 2016;77(2):e190-8.
8 Inglis A, Koehn D, Mcgillivray B, Stewart SE, Austin J. Evaluating a unique, specialist psychiatric genetic counseling clinic: uptake and impact. Clin Genet. 2015;87(3):218-24.

9 Moldovan R, Pintea S, Austin J. The efficacy of genetic counseling for psychiatric disorders: a meta-analysis. J Genet Couns. 2017; 26(6):1341-7.

10 Besterman AD, Moreno-DeLuca D, Nurnberger JI. 21st-century genetics in psychiatric residency training. How do we get there? JAMA Psychiatry. 2019;76:1541-6.

11 Bourdon JL, Hettema JM, Prom-Wormley EC, Southam-Gerow MA. Assessing stakeholder perceptions of the utility of genetic information for the clinical care of mental health disorders: we have a will but need to see the way. Adm Policy Ment Health. 2020 Jun. Epub ahead of print.

12 Dick DM. Commentary for special issue of Prevention Science "Using genetics in prevention: science fiction or science fact?" Prev Sci. 2018 Jan;19(1):101-108.

13 Doerr M, Teng K. Family history: still relevant in the genomics era. Cleve Clin J Med. 2012; 79(5):331-6.

14 Salm M, Abbate K, Appelbaum P, Ottoman R, Chung W, Marder K, et al. Use of genetic tests among neurologists and psychiatrists: Knowledge, attitudes, behaviors, and needs for training. J Gen Couns. 2014;23(2):156-63.
15 Sperber NR, Carpenter JS, Cavallari LH, Damschroder LJ, Cooper-Dehoff RM, Denny JC, Orlando LA. Challenges and strategies for implementing genomic services in diverse settings: experiences from the implementing geNomics In pracTicE (IGNITE) network. BMC Med Genomics. 2017 May 22;10(1):35.

16 Visscher PM, Wray NR, Zhang Q, Sklar P, McCarthy MI, Brown MA, et al. 10 years of GWAS discovery: biology, function, and translation. Am J Hum Genet. 2016;101(1): 5-22.

17 Cornel MC, van El CG. Barriers and facilitating factors for implementation of genetic services: a public health perspective. Front Public Health. 2017;5:195.

18 Gil F, Méndez I, Sirgo A, Llort G, Blanco I, Cortés-Funes H. Perception of breast cancer risk and surveillance behaviours of women with family history of breast cancer: a brief report on a Spanish cohort. Psychooncology. 2003;12(8):821-7.

19 Macdonald DJ, Sarna L, Weitzel JN, Ferrell B. Women's perceptions of the personal and family impact of genetic cancer risk assessment: focus group findings. J Genet Couns. 2009;19(2):148-60.

20 Norman P, Brain K. An application of an extended health belief model to the prediction of breast self-examination among women with a family history of breast cancer. $\mathrm{Br} \mathrm{J}$ Health Psychol. 2005;10(Pt 1):1-16. 
21 Phillips K, Jenkins M, Lindeman G, McLachlan S, McKinley J, Weideman P, et al. Riskreducing surgery, screening and chemoprevention practices of BRCA 1 and BRCA2 mutation carriers: a prospective cohort study. Clin Genet. 2006;70(3):198-206.

22 Arnett DK, Baird AE, Barkley RA, Basson CT, Boerwinkle E, Ganesh SK, et al. Relevance of genetics and genomics for prevention and treatment of cardiovascular disease: a scientific statement from the American heart association council on epidemiology and prevention, the stroke council, and the functional genomics and translational biology interdisciplinary working group. Circulation. 2007;115(22):2878-901.

23 Ebomoyi W. Genomic epidemiology of cardiovascular disease, adoption of the health belief model to increase screening for known risk factors and use of natural approaches to enhance heart health. J Cardiovasc Dis Diagn. 2013;1(5).

24 Ginsberg GS, Willard HF. Genomics and personalized medicine: Foundations and applications. Transl Res. 2009;154(6):278-87.

25 Khera AV, Kathiresan S. Genetics of coronary artery disease: discovery, biology and clinical translation. Nat Rev Genet. 2017;18(6):33144.

26 Chan IS, Ginsberg GS. Personalized medicine: progress and promises. Annu Rev Genomics Hum Genet. 20110;121:2176-244.

27 Black JR, Clark SJ. Age-related macular degeneration: genome-wide association studies to translation. Genet Med. 2016;18(4):283-9.

28 Taber JM, Aspinwall LG, Stump TK, Kohlmann W, Champine M, Leachman SA. Genetic test reporting enhances understanding of risk information and acceptance of prevention recommendations compared to family history-based counseling alone. J Behav Med. 2015;38(5):740-53.

29 Fernandez CV, Strahlendorf C, Avard D, Knoppers BM, O'Connell C, Bouffet E, et al. Attitudes of Canadian researchers toward the return to participants of incidental and targeted genomic findings obtained in a pediatric research setting. Genet Med. 2013;15(7): 558-64.

30 Kimball BC, Nowakowski KE, Maschke KJ, McCormick JB. Genomic data in the electronic medical record: perspectives from a biobank community advisory board. J Empir Res Hum Res Ethics. 2014;9(5):16-24.

31 Sullivan PF, Agrawal A, Bulik CM, Andreassen OA, BørglumBreen ADG, Breen G, et al Psychiatric genomics: an update and an agenda. Ajp. 2018;175(1):15-27.

32 Sullivan PF, Daly MJ, O'Donovan M. Genetic architectures of psychiatric disorders: the emerging picture and its implications. Nat Rev Genet. 2012;13(8):537-51.

33 Kysh L. What's in a name? The difference between a systematic review and a literature review and why it matters. 2019. Available from: https: //guides.libraries.psu.edu/c.php?g= $319063 \& p=5222056$.
34 Polderman TJ, Benyamin B, de Leeuw CA, Sullivan PF, van Bochoven A, Visscher PM, et al. Meta-analysis of the heritability of human traits based on fifty years of twin studies. Nat Genet. 2015;47(7):702-9.

35 Neale BM, Ferreira MAR, Medland SE, Posthuma D. Statistical genetics: gene mapping through linkage and association. New York, NY: Taylor \& Francis Group; 2008.

36 van der Laan AL, Boenink M. Beyond bench and bedside: disentangling the concept of translational research. Health Care Anal. 2012;23(1):32-49.

37 Cornetta K, Brown CG. Balancing personalized medicine and personalized care. Acad Med. 2013;88(3):309-13.

38 Legare F, Robitaille H, Gane C, Hebert J, Labrecque M, Rousseau F. Improving decision making about genetic testing in the clinic: an overview of effective knowledge translation interventions. PLoS One. 2016;11(3): e0150123.

39 Khoury MJ, Gwinn M, Yoon PW, Dowling N, Moore CA, Bradley L. The continuum of translation research in genomic medicine: how can we accelerate the appropriate integration of human genome discoveries into health care and disease prevention? Genet Med. 2007;9(10):665-74.

40 Waldman SA, Terzic A. Clinical and translational science: from bench-bedside to global village. Clin Transl Sci. 2010;3(5):254-7.

41 Collins FS, Varmus H. A new initiative on precision medicine. $\mathrm{N}$ Engl J Med. 2015; 372(9):793-5.

42 Jameson JL, Longo DL. Precision medicine: personalized, problematic, and promising. $\mathrm{N}$ Engl J Med. 2015;372(23):2229-34.

43 Bubier JA, Chesler EJ. Accelerating discovery for complex neurological and behavioral disorders through systems genetics and integrative genomics in the laboratory mouse. Neurotherapeutics. 2012;9(2):338-48.

44 Driscoll CA, Barr CS. Studying longitudinal trajectories in animal models of psychiatric illness and their translation to the human condition. Neurosci Res. 2016;102:67-77.

45 Falk A, Heine VM, Harwood AJ, Sullivan PF, Peitz M, Brüstle O, et al. Modeling psychiatric disorders: from genomic findings to cellular phenotypes. Mol Psychiatry. 2016;21(9): 1321-79.

46 Gardner PD, Tapper AR, King JA, DiFranza JR, Ziedonis DM. The neurobiology of nicotine addiction: clinical and public policy implications. J Drug Issues. 2009;39(2):417-41.

47 Glatt CE, Lee FS. Common polymorphisms in the age of research domain criteria (RDoC): integration and translation. Biol Psychiatry. 2016;79(1):25-31.

48 LeFoll B, Pushparaj A, Pryslawsky Y, Forget B, Vemuri K, Makriyannis A, et al. Translational strategies for therapeutic development in nicotine addiction: rethinking the conventional bench to bedside approach. Prog Neuropsychopharmacol Biol Psychiatry. 2014;52: 86-93.
49 Lobo DS, Aleksandrova L, Knight J, Casey DM, el-Guebaly N, Nobrega JN, et al. Addiction-related genes in gambling disorders: new insights from parallel human and pre-clinical models. Mol Psychiatry. 2015;20(8):1002-10.

50 Malter CM, Tottneham N, Casey BJ. Translational developmental studies of stress on brain and behavior: implications for adolescent mental health and illness. Neuroscience. 2013;249:53-62.

51 Veenstra-VanderWeele J, Blakely RD. Networking in autism: leveraging genetic, biomarker and model system findings in the search for new treatments. Neuropsychopharmacology. 2012;37(1):196-212.

52 Vinkers $\mathrm{CH}$, van Bogaert $\mathrm{MJ}$, Klanker $\mathrm{M}$, Korte SM, Oosting R, Hanania T, et al. Translational aspects of pharmacological research into anxiety disorders: the stress-induced hyperthermia (SIH) paradigm. Eur J Pharmacol. 2008;585(2-3):407-25.

53 Brown AS, Meyer U. Maternal immune activation and neuropsychiatric illness: a translational research perspective. Am J Psychiatry. 2018;175(11):1073-83

54 Sestan N, State MW. Lost in translation: traversing the complex path from genomics to therapeutics in autism spectrum disorder. Neuron. 2018;100(2):406-23.

55 Silverman JL, Ellegood J. Behavioral and neuroanatomical approaches in models of neurodevelopmental disorders: opportunities for translation. Curr Opini Neurol. 2018;31:12633.

56 Hack LM, Fries GR, Eyre HA, Bousman CA, Singh AB, Quevedo J, et al. Moving pharmacoepigenetics tools for depression toward clinical use. J Affect Disord. 2019;249:336-46.

57 Hartwell EE, Kranzler HR. Pharmacogenetics of alcohol use disorder treatments: an update. Expert Opin Drug Metab Toxicol. 2019;15(7): 553-64.

58 Hippman C, Nislow C. Pharmacogenomic testing: clinical evidence and implementation challenges. Jpm. 2019;9(3):40-25.

59 Peterson RE, Kuchenbaecker K, Walters RK, Chen CY, Popejoy AB, Periyasamy S, et al. Genome-wide association studies in ancestrally diverse populations: opportunities, methods, pitfalls, and recommendations. Cell. 2019;179(3):589-603.

60 Reay WR, Atkins JR, Carr VJ, Green MJ, Cairns MJ. Pharmacological enrichment of polygenic risk for precision medicine in complex disorders. Sci Rep. 2020;10(1):879-91.

61 Saccone NL, Baurley JW, Bergen AW, David SP, Elliott HR, Foreman MG, et al. The Value of biosamples in smoking cessation trials: a review of genetic, metabolomic, and epigenetic findings. Nicotine Tob Res. 2018;20(4): 403-13.

62 Need AC, Goldstein DB. Neuropsychiatric genomics in precision medicine: diagnostics, gene discovery, and translation. Dialogues Clin Neurosci. 2016;18(3):237-52. 
63 Insel TR, Voon V, Nye JS, Brown VJ, Altevogt $\mathrm{BM}$, Bullmore ET, et al. Innovative solutions to novel drug development in mental health. Neurosci Biobehav Rev. 2013;37(10 Pt 1): 2438-44.

64 Jia F, Shan L, Wang B, Li H, Miao C, Xu Z, et al. Bench to bedside review: possible role of vitamin $\mathrm{D}$ in autism spectrum disorder. Psychiatry Res. 2017;6:360-5.

65 Luoni A, Riva MA. MicroRNAs and psychiatric disorders: from aetiology to treatment. Pharmacol Ther. 2016;167:13-27.

66 Ursano RJ, Zhang L, Li H, Johnson L, Carlton J, Fullerton CS, et al. PTSD and traumatic stress: from gene to community and bench to bedside. Brain Res. 2009;1293:2-12.

67 Hariri AR, Holmes A. Finding translation in stress research. Nat Neurosci. 2015;18(10) 1347-52.

68 Kaiser T, Feng G. Modeling psychiatric disorders for developing effective treatments. Nat Med. 2015;21(9):979-88.

69 Plummer JT, Gordon AJ, Levitt P. The genetic intersection of neurodevelopmental disorders and shared medical comorbidities: relations that translate from bench to bedside. Front Psychiatry. 2016;7:142.

70 Sweatt JD, Tamminga CA. An epigenomics approach to individual differences and its translation to neuropsychiatric conditions. Dialogues Clin Neurosci. 2016;18(3):289-98.

71 Beversdorf DQ. Phenotyping, etiological factors, and biomarkers: toward precision medicine in autism spectrum disorders. J Dev Behav Pediatr. 2016;37(8):659-73.

72 Cuthbert BN, Insel TR. Toward the future of psychiatric diagnosis: the seven pillars of RDoC. BMC Med. 2013;11:126.

73 Dalvie S, Koen N, McGregor N, O'ConnellWarnich KL, Warnich L, Ramesar $\mathrm{R}$, et al. Toward a global roadmap for precision medicine in psychiatry: challenges and opportunities. OMICS. 2016;20(10):557-64.

74 Drake RE, Cimpean D, Torrey WC. Shared decision making in mental health: prospects for personalized medicine. Dialogues Clin Neurosci. 2009;11(4):455-63.

75 Finucane B, Challman TD, Martin CL, Ledbetter DH. Shift happens: family background influences clinical variability in genetic neurodevelopmental disorders. Genet Med. 2016; 18(4):302-4.

76 Gandal MJ, Leppa V, Won H, Parikshak NN Geschwind DH. The road to precision psychiatry: translating genetics into disease mechanisms. Nat Neurosci. 2016;19(11) 1397-407.

77 Geschwind DH. DNA microarrays: translation of the genome from laboratory to clinic. Lancet Neurol. 2003;2(5):275-82.

78 Hess GP, Fonseca E, Scott R, Fagerness J. Pharmacogenomic and pharmacogeneticguided therapy as a tool in precision medicine: current state and factors impacting acceptance by stakeholders. Genet Res. 2015;97:e13.
79 Murck H, Laughren T, Lamers F, Picard R, Walther S, Goff D, et al. Taking personalized medicine seriously: biomarker approaches in phase IIb/III studies in major depression and schizophrenia. Innov Clin Neurosci. 2015; 12(3-4):26S-40S

80 Ozomaro U, Wahlestedt C, Nemeroff CB. Personalized medicine in psychiatry: problems and promises. BMC Med. 2013;11:132.

81 Shin C, Han C, Pae C, Patkar AA. Precision medicine for psychopharmacology: a general introduction. Expert Rev Neurother. 2016; 16(7):831-9.

82 Chen L-S, Zawertailo L, Piasecki TM, Kaprio J, Foreman M, Elliott HR, et al. Leveraging genomic data in smoking cessation trials in the era of precision medicine: why and how. Nicotine Tob Res. 2018;20(4):414-24.

83 Hoehe MR, Morris-Rosendahl DJ. The role of genetics and genomics in clinical psychiatry. Dialogues Clin Neurosci. 2018;20:160-77.

84 Allenby CE, Boylan KA, Lerman C, Falcone M. Precision medicine for tobacco dependence: development and validation of the nicotine metabolite ratio. J Neuroimmune Pharmacol. 2016;11(3):471-83.

85 Bierut LJ, Johnson EO, Saccone NL. A glimpse into the future: personalized medicine for smoking cessation. Neuropharmacology. 2014;76:592-9.

86 Blum K, Modestnio EJ, Gondre-Lewis MC, Neary J, Siwicki D, Hauser M, et al. Global opioid epidemic: doomed to fail without genetically based precision addiction medicine $\left(\mathrm{PAM}^{\mathrm{s}}\right)$ : lessons learned from America. Precision Medicine. 2017;2(1):17-22.

87 Daws S. Ethical application of precision medicine to schizophrenia management. New Bioeth. 2017;23(2):147-53.

88 Evers K. Personalized medicine in psychiatry: ethical challenges and opportunities. Dialogues Clin Neurosci. 2009;11(4):427-34.

89 Geschwind DH, State MW. Gene hunting in autism spectrum disorder: on the path to precision medicine. Lancet Neurol. 2015;14(11): 1109-20.

90 Helton SG, Lohoff FW. Pharmacogenetics of alcohol use disorders and comorbid psychiatric disorders. Psychiatry Res. 2015;230(2): 121-9.

91 Hsin-Ya L, Jih-Heng L, Uuh-Ling T, WeiChiao C, Tze-Chun T, Liu R-H. Moving toward personalized medicine in the methadone maintenance treatment program: a pilot study on the evaluation of treatment responses in Taiwan. Biomed Res Int. 2013:1-11.

92 Jurgens G, Jacobsen CB, Rasmussen HB, Werge T, Nordentoft M, Andersen SE. Utility and adoption of CYP2D6 and CYP2C19 genotyping and its translation into psychiatric clinical practice. Acta Psychiatrica Scandinavica. 2012;125:228-37.

93 Lally J, Gaughran F, Timms P, Curran SR. Treatment-resistant schizophrenia: current insights on the pharmacogenomics of antipsychotics. Pharmgenomics Pers Med. 2016; 9(9):117-29.
94 Lee BS, McIntyre RS, Gentle JE, ParkChiriboga NSDA, Chiriboga DA, Lee Y, et al. A computational algorithm for personalized medicine in schizophrenia. Schizophr Res. 2017;192:131-6.

95 Lett T, Walter H, Brandl EJ. Pharmacogenetics and imaging-pharmacogenetics of antidepressant response: towards translational strategies. CNS Drugs. 2016;30(12):116989.

96 Malhotra AK, Lencz T, Correll CU, Kane JM. Genomics and the future of pharmacotherapy in psychiatry. Int Rev Psychiatry. 2007;19(5):523-30.

97 Myers AJ, Nemeroff CB. New vistas in the management of treatment-refractory psychiatric disorders: genomics and personalized medicine. Foc. 2010;8(4):525-35.

98 Niculescu A, Le-Niculescu H, Levey DF, Phalen PL, Dainton HL, Roseberry K, et al. Precision medicine for suicidality: from universality to subtypes and personalization. Mol Psychiatry. 2017;22(9):1250-73.

99 Patriquin MA, Bauer IE, Soares JC, Graham DP, Nielsen DA. Addiction pharmacogenetics: a systematic review of the genetic variation of the dopaminergic system. Psychiatr Genet. 2015;25(5):181-93.

100 Prendes-Alvarez S, Nemeroff CB. Personalized medicine: prediction of disease vulnerability in mood disorders. Neurosci Lett. 2018;669(669):10-3.

101 Ragia G, Manolopoulos V. Personalized medicine of alcohol addiction: pharmacogenomics and beyond. Curr Pharm Biotechnol. 2017;18(3):221-30.

102 Alhajji L, Nemeroff CB. Personalized medicine and mood disorders. Psychiatr Clin North Am. 2015;38(3):395-403.

103 Bloss CS, Jeste DV, Schork NJ. Genomics for disease treatment and prevention. Psychiatr Clin North Am. 2011;34(1):147-66.

104 Costa JA. Personalized medicine in psychiatry: new technologies and approaches. Metab Clin Exp. 2013;62(Suppl 1):S40-4.

105 deLeon J. The future (or lack of future) of personalized prescription in psychiatry. Pharmacol Res. 2009;59(2):81-9.

106 Fraguas D, Díaz-Caneja CM, State MW, O'Donovan MC, Gur RE, Arango C. Mental disorders of known aetiology and precision medicine in psychiatry: a promising but neglected alliance. Psychol Med. 2017;47(2): 193-7.

107 Singh AB, Bousman CA, Ng C, Berk M. Antidepressant pharmacogenetics. Curr Opin Psychiatry. 2014;27(1):43-51.

108 Martin AR, Kanai M, Kamatani Y, Okada Y, Neale BM, Daly MJ. Clinical use of current polygenic risk scores may exacerbate health disparities. Nat Genet. 2019;51(4):584-91.

109 Martin AR, Daly MJ, Robinson EB, Hyman SE, Neale BM. Predicting polygenic risk of psychiatric disorders. Biol Psychiatry. 2019; 86(2):97-109. 
110 Menke A. Precision pharmacotherapy: psychiatry's future direction in preventing, diagnosing, and treating mental disorders. Pharmgenomics Pers Med. 2018;11:211-22.

111 Posner J. The role of precision medicine in child psychiatry: what can we expect and when? J Am Acad Child Adolesc Psychiatry. 2018;57(11):813-7.

112 Rees E, Owen MJ. Translating insights from neuropsychiatric genetics and genomics for precision psychiatry. Genome Med. 2020; 12(1):43-59.

113 Bradley P, Shiekh M, Mehra V, Vrbicky K, Layle S, Olson MC, et al. Improved efficacy with targeted pharmacogenetic-guided treatment of patients with depression and anxiety: a randomized clinical trial demonstrating clinical utility. J Psychiatr Res. 2018; 96:100-7.

114 Menke A, Weber H, Deckert J. Roadmap for routine pharmacogenetic testing in a psychiatric university hospital. Pharmacopsychiatry. 2020 Jul;53(4):179-83.

115 Bousman C, Maruf AA, Muller DJ. Towards the integration of pharmacogenetics in psychiatry: a minimum, evidence-based genetic testing panel. Curr Opin Psychiatry. 2019; 32(1):7-15.

116 Perugi G, De Rossi P, Fagiolini A, Girardi P, Maina G, Sani G, et al. Personalized and precision medicine as informants for treatment management of bipolar disorder. Int Clin Psychopharmacol. 2019;34(4):189-205.

117 Tomasi J, Lisoway AJ, Zai CC, Harripaul R, Müller DJ, Zai GCM, et al. Towards precision medicine in generalized anxiety disorder: review of genetics and pharmaco(epi) genetics. J Psychiatr Res. 2019;119:33-47.

118 Wehry AM, Ramsey L, Dulemba SE, Mossman SA, Strawn JR. Pharmacogenomic testing in child and adolescent psychiatry: an evidence-based review. Curr Probl Pediatr Adolesc Health Care. 2018;48(2):40-9.

119 Damianco CR, Mazefsky CA, White S, Dichter GS. Future directions for research in autism spectrum disorders. J Clin Child Adolesc Psychol. 2014;43:828-43.

120 Foley C, Corvin A, Nakagome S. Genetics of schizophrenia: ready to translate? Curr Psychiatry Rep. 2017;19(9):61.

121 Siegel SD, Lerman C, Flitter A, Schnoll RA. The use of the nicotine metabolite ratio as a biomarker to personalize smoking cessation treatment: current evidence and future directions. Cancer Prev Res. 2020;13(3):26172 .

122 Stern S, Linker S, Vadodaria KC, Marchetto MC, Gage FH. Prediction of response to drug therapy in psychiatric disorders. Open Biol. 2018;8(5):180031.

123 Zayats T, Neale BM. Recent advances in understanding of attention deficit hyperactivity disorder (ADHD): how genetics are shaping our conceptualization of this disorder. F1000Res. 2020;8:1-8.
124 Hutchison KE. Substance use disorders: realizing the promise of pharmacogenomics and personalized medicine. Annu Rev Clin Psychol. 2010;6:577-89.

125 Wium-Andersen IK, Vinberg M, Kessing LV, McIntyre RS. Personalized medicine in psychiatry. Nord J Psychiatry. 2016;71(1): 12-9.

126 Serretti A. The present and future of precision medicine in psychiatry: focus on clinical psychopharmacology of antidepressants. Clin Psychopharmacol Neurosci. 2018; 16(1):1-6.

127 Amare AT, Schubert KO, Baune BT. Pharmacogenomics in the treatment of mood disorders: strategies and opportunities for personalized psychiatry. EPMA J. 2017;8(3): 211-27.

128 Bickman L, Lyon AR, Wolpert M. Achieving precision mental health through effective assessment, monitoring, and feedback processes : introduction to the special issue. Adm Policy Ment Health. 2016;43(3):271-6.

129 Wittchen HU, Knappe S, Andersson G, Araya R, Banos Rivera RM, Barkham M, et al. The need for a behavioural science focus in research on mental health and mental disorders. Int J Methods Psychiatr Res. 2014; 23(Suppl 1):28-40.

130 Herbert D, Neves-Pereira M, Baidya R, Cheema S, Groleau S, Shahmirian A, et al. Genetic testing as a supporting tool in prescribing psychiatric medication: design and protocol of the IMPACT study. J Psychiatr Res. 2018;96:265-72.

131 Ramsey AT, Chen LS, Hartz SM, Saccone NL, Fisher SL, Proctor EK, et al. Toward the implementation of genomic applications for smoking cessation and smoking-related diseases. Transl Behav Med. 2018;8(1):7-17.

132 Atkins MS, Rusch D, Mehta TG, Lakind D. Future direction for dissemination and implementation science: aligning ecological theory and public health to close the research to practice gap. J Clin Child Adolesc Psychol. 2016;45:215-26.

133 Chambers DA, Azrin ST. Partnership: a fundamental component of dissemination and implementation research. Psychiatr Serv. 2013;64:509-11.

134 Glasgow RE, Vinson C, Chambers D, Khoury MJ, Kaplan RM, Hunter C. National Institutes of Health approaches to dissemination and implementation science: current and future directions. Am J Public Health. 2012;102(7):1274-81.

135 Brownson RC, Colditz GA, Proctor EK. Dissemination and implementation research in health: translating science to practice. New York, NY: Oxford University Press; 2018.

136 Brownson RC, Eyler AA, Harris JK, Moore JB, Tabak RG. Getting the word out: new approaches for disseminating public health science. J Public Health Manag Pract. 2017; 24:102-11.
137 Colditz GA, Emmons KM. The promise and challenges of dissemination and implementation research. In: Brownson RC, Colditz GA, Proctor EK, editors. Dissemination and implementation research in health: translating science to practice. New York, NY: Oxford University Press; 2018.

138 Drury S, Cuthbert B. Advancing pediatric psychiatry research: linking neurobiological processes to novel treatment and diagnosis through the research domain criteria (RDoC) project. Ther Innov Regul Sci. 2015; 49(5):643-6.

139 Finn CT, Smoller JW. Genetic counseling in psychiatry. Harv Rev Psychiatry. 2006;14(2): 109-21.

140 Harold GT, Leve LD, Sellers R. How can genetically informed research help inform the next generation of interparental and parenting interventions? Child Dev. 2017;88(2): 446-58.

141 Hendershot CS. Pharmacogenetic approaches in the treatment of alcohol use disorders: addressing clinical utility and implementation thresholds. Addict Sci Clin Pract. 2014;9(1):20.

142 Roos JL. Genetics of schizophrenia: communicating scientific findings in the clinical setting. Afr J Psychiatry. 2011;14(2):105-11.

143 Vortsman JA, Parr JR, Moreno-De-Luca D, Anney RJ, Nurnberger JI Jr, Hallmayer JF. Autism genetics: opportunities and challenges for clinical translation. Nat Rev Genet. 2017;18:362-76.

144 Brown L, Eum S, Haga SB, Strawn JR, Ziehut $\mathrm{H}$. Clinical utilization of pharmacogenetics in psychiatry: perspectives of pharmacists, genetic counselors, implementation science, clinicians, and industry. Pharmacopsychiatry. 2020;53(4):162-73.

145 Chiu A, Hartz S, Smock N, Chen J, Qazi A, Onyeador J, et al. Most current smokers desire genetic susceptibility testing and genetically-efficacious medication. J Neuroimmune Pharmacol. 2018;13(4):430-7.

146 Belsky DW, Moffitt TE, Caspi A. Genetics in population health science: strategies and opportunities. Am J Public Health. 2012; 103(Suppl 1):S73-83.

147 McBride CM. Translational research to apply genomics to improve health promotion: is it worth the investment? Transl behav Med. 2018;8(1):54-8.

148 Bradshaw CP, Haynes KT. Building a science of partnership-focused research: forging and sustaining partnerships to support child mental health prevention and services research. Adm Policy Ment Health. 2012;39(4):221-4.

149 Meiser B, Peate M, Levitan C, Mitchell PB, Trevena L, Barlow-Stewart K, et al. A psycho-educational intervention for people with a family history of depression: pilot results. J Genet Couns. 2017;26(2):312-21.

150 deLeon J. AmpliChip CYP450 Test: personalized medicine has arrived in psychiatry. Expert Rev Mol Diagn. 2006;6(3):277-86. 
151 Ostergren JE, Hammer RR, Dingel MJ, Koenig BA, McCormick JB. Challenges in translational research: the views of addiction scientists. PLoS One. 2014;9(4):e93482-6.

152 Phillips JM, Siegel SJ, Shields AE, Patterson F, Gould TJ, strasser AA, et al. Translating basic science to improve pharmacotherapy for nicotine dependence. Nicotine Tob Res. 2007;9(Suppl 4):S583-98.

153 Smoller JW, Andreassen OA, Edenberg HJ, Faraone SV, Glatt SJ, Kendler KS. Psychiatric genetics and the structure of psychopathology. Mol Psychiatry. 2018;24(3):409-20.

154 Donaldson ZR, Hen R. From psychiatric disorders to animal models: a bidirectional and dimensional approach. Biol Psychiatry. 2015;77(1):15-21.

155 Rende R, Slomkowski C. Incorporating the family as a critical context in genetic studies of children: implications for understanding pathways to risky behavior and substance use. J Pediatr Psychol. 2008;34(6):606-16.
156 Smoller JW. The genetics of stress-related disorders: PTSD, depression, and anxiety disorders. Neuropsychopharmacology. 2016;41(1):297-319.

157 Uher R. Genes, environment, and individual differences in responding to treatment for depression. Harv Rev Psychiatry. 2011; 19(3):109-24.

158 Bulik CM, Blake L, Austin J. Genetics of eating disorders: what the clinician needs to know. Psychiatry Clin North Am. 2019; 42(1):59-73.

159 Gerretsen P, Müller DJ, Tiwari A, Mamo D, Pollock BG. The intersection of pharmacology, imaging, and genetics in the development of personalized medicine. Dialogues Clin Neurosci. 2009;11(4):363-76.
160 Addington AM, Rapoport JL. Annual research review: impact of advances in genetics in understanding developmental psychopathology. J Child Psychol Psychiatry. 2012; 53(5):510-8.

161 Garner M, Möhler H, Stein DJ, Mueggler T, Baldwin DS. Research in anxiety disorders: from the bench to the bedside. Eur Neuropsychopharmacol. 2009;19(6):381-90.

162 Walden LM, Brandl EJ, Changasi A, Sturgess JE, Soibel A, Notario JF, et al. Physicians' opinions following pharmacogenetic testing for psychotropic medication. Psychiatry Res. 2015;229(3):913-8.

163 Holmes MV, Shah T, Vickery C, Smeeth L, Hingorani AD, Casas JP. Fulfilling the promise of personalized medicine? Systematic review and field synopsis of pharmacogenetic studies. PLoS One. 2009;4(12): e7960.

164 Fullerton JM, Nurnberger JI. Polygenic risk scores in psychiatry: will they be useful for clinicians? F1000Res. 2019;8:1. 